\title{
ANALISIS FAKTOR PENYEBAB PERILAKU TANTRUM PADA ANAK AUTIS
}

\author{
Firdaus, Wesiana Herisanti \\ Keperawatan, Universitas Nahdlatul Ulama Surabaya \\ Email: firdaus@unusa.ac.id
}

\begin{abstract}
Autism is a complex developmental disorder, classified as extraordinary children are very diverse, insecure, aggressive, responding less or even excessively to an external stimuli, and move their limbs unnaturally and can affect their behavior, namely tantrums, Parents determine the level of improvement that needs to be achieved by the child. this research is aimed to find out the factors caused to the behavior of autistic children in Nathanisa Foundation, SurabayaThis research uses quantitative design with cross sectional research design. The sample was taken by simple random sampling technique. Using primary data, by anamnesing the autistic child and the mother of the autistic child. Data analysis uses a statistical binary logistic regression test. From the binary logistic regression test results obtained that the most influential on tantrum behavior is the support of parents about a glutein-free and casein-free diet with a result of $p=0,000$ Parental support in preparing children for nutrition is very important because glutein and casein will increase tantrums in children. It is expected that parents always pay attention to autistic children so tantrums do not occur.
\end{abstract}

Keywords: Family Support, Education, Employment, Tantrum Behavior

\begin{abstract}
ABSTRAK
Autisme adalah gangguan perkembangan yang kompleks, diklasifikasikan sebagai anak-anak luar biasa yang sangat beragam, tidak aman, agresif, kurang menanggapi atau bahkan berlebihan terhadap rangsangan eksternal, dan menggerakkan anggota tubuh mereka secara tidak wajar dan dapat memengaruhi perilaku mereka, yaitu amukan, Orang tua menentukan tingkat peningkatan yang perlu dicapai oleh anak. Penelitian ini bertujuan untuk mengetahui faktor-faktor yang menyebabkan perilaku anak autis di Yayasan Nathanisa, Surabaya. Penelitian ini menggunakan desain kuantitatif dengan desain penelitian cross-sectional. Sampel diambil dengan teknik simple random sampling. Menggunakan data primer, dengan menganalisis anak autis dan ibu dari anak autis. Analisis data menggunakan uji regresi logistik biner statistik. Dari hasil uji regresi logistik biner diperoleh bahwa yang paling berpengaruh pada perilaku tantrum adalah dukungan orang tua tentang diet bebas gluten dan kasein dengan hasil $p=0,000$. Dukungan orang tua dalam mempersiapkan anak untuk gizi sangat penting karena gluten dan kasein akan meningkatkan amukan pada anak-anak. Diharapkan orang tua selalu memperhatikan anak-anak autis sehingga amukan tidak terjadi.
\end{abstract}

Kata kunci: Dukungan Keluarga, Pendidikan, Pekerjaan, Perilaku tantrum 


\section{PENDAHULUAN}

Autisme adalah gangguan perkembangan yang kompleks, dan diklasifikasikan sebagai anak-anak luar biasa yang sangat beragam. Pada anak autisme sering terjadi marah, gangguan kognitif dan kemauan. Dalam hal perilaku, anakanak dengan autisme sering melukai diri mereka sendiri, kurang percaya diri, menjadi agresif, bereaksi yang berlebihan terhadap rangsanganrangsangan dari eksternal, dan menggerakkan anggota tubuh mereka secara tidak wajar dan hal tersebut bisa mempengaruhi pada perilakunya yaitu tantrum (mengamuk). Perilaku tantrum terjadi ketika anak terhalangi untuk melakukan sesuatu yang mereka inginkan. ${ }^{1}$

Direktur Pengembangan Kesehatan Mental Kementerian Kesehatan Pada tahun 2013 menduga jumlah anak autis di Indonesia sekitar 112.000 dengan rentang 5-19 tahun. Angka ini berdasarkan hitungan prevalensi autis sebesar 1,68 per 100 anak di bawah 15 tahun. Pada tahun 2015 di Indonesia, diperkirakan terdapat 12.800 anak penyandang autisme dan 134.000 penyandang spektrum autis. ${ }^{2}$

Perkiraan prevalensi autisme di Eropa pada anak usia 8 tahun pada tahun 2012 adalah 1:68 anak dengan kejadian yang jauh lebih tinggi pada anak laki-laki (23,6 per 1.000) dibandingkan pada anak perempuan (5,3 per 1.000). Selama dekade terakhir, tingkat autisme semakin meningkat, sementara peningkatan kesadaran, kekhawatiran dan kriteria diagnostik autis telah berkembang. ${ }^{3}$
Faktor-faktor yang memengaruhi terjadinya tantrum adalah orang tua. Orang tua mempunyai peranan sangat penting karena yang merawat, mengasuh sehari hari terutama pada ibu. Nurdiansyah mengatakan orang tua merawat anak autis ditentukan oleh peran dan dukungan penuh dari orang tua atau keluarga. ${ }^{4}$ Ketika anak merengek meminta makanan sedangkan makanan itu tidak boleh dikonsumsi, orang tua harus bijaksana, tidak mengikuti kemauan anak meskipun anak tersebut merengek, berguling-guling, dan berteriak teriak. Hal ini dibuktikan dengan sebuah hasil penelitian yang menyatakan perilaku tantrum umumnya dialami oleh anak autis yang mengekspresikan kemarahan mereka dengan tidur dilantai, meronta-ronta, berteriak dan biasanya menahan napas. Tujuan penelitian ini adalah mengetahui faktor-faktor yang berhubungan dengan perilaku tantrum di Yayasan Nathanisa, Surabaya.

\section{METODE PENELITIAN}

Penelitian ini menggunakan desain analitik observasional dengan pendekatan cross sectional. Populasi dan sampel penelitian adalah Ibu yang mempunyai anak autis. Sampel diambil dengan teknik simple random sampling. Variabel independen adalah faktor yang memengaruhi perilaku tantrum sedangkan variabel dependen adalah perilaku tantrum. Instrument penelitian menggunakan kuesioner dan dianalisis menggunakan uji Chi square dan Regresi linear. 


\section{HASIL DAN PEMBAHASAN}

Dari 50 responden, peneliti mendapatkan $76 \%$ anak autis berjenis kelamin laki, $78 \%$ pendidikan orang tua anak autis adalah perguruan tinggi, $68 \%$ orang tua anak autis tidak bekerja, dan $66 \%$ orang tua anak autis mendukung tentang diet glutein.

Tabel 1. Distribusi Responden Berdasarkan Jenis Kelamin, Pendidikan Ibu, Pekerjaan Orang Tua (Ibu) dan Dukungan Orang Tua tentang Diet Free Glutein dan Casein

\begin{tabular}{llcc}
\hline No & \multicolumn{1}{c}{ Karakteristik } & $\mathrm{n}$ & $(\%)$ \\
\hline 1. & Jenis Kelamin & & \\
& a. Laki-laki & 38 & 76,0 \\
& b. Perempuan & 12 & 24,0 \\
\hline 2. & Pendidikan orang tua & & \\
& (ibu) & & \\
& a. Dasar & 0 & 0,0 \\
& b. Menengah & 11 & 22,0 \\
& c. Perguruan tinggi & 39 & 78,0 \\
\hline 3. Pekerjaan orang tua (ibu) & & \\
& a. Bekerja & 16 & 32,0 \\
& b. Tidak bekerja & 34 & 68,0 \\
\hline 4. & Dukungan Keluarga & & \\
& a. Mendukung & 33 & 66,0 \\
& b. Tidak mendukung & 17 & 34,0 \\
\hline
\end{tabular}

\section{Jenis Kelamin}

Tabel 2. Tabulasi Silang Jenis Kelamin dengan Perilaku Tantrum

\begin{tabular}{lccc}
\hline Jenis & \multicolumn{3}{c}{ Perilaku Tantrum } \\
\cline { 2 - 4 } Kelamin & $\begin{array}{c}\text { Tidak } \\
\text { tantrum } \\
\mathrm{n}(\%)\end{array}$ & $\begin{array}{c}\text { Tantrum } \\
\mathrm{n}(\%)\end{array}$ & $\begin{array}{c}\text { Total } \\
\mathrm{n}(\%)\end{array}$ \\
\hline Laki-laki & 21 & 17 & 38 \\
& $(55,3 \%)$ & $(44,7 \%)$ & $(100,0 \%)$ \\
Perempuan & 9 & 3 & 12 \\
& $(75,0 \%)$ & $(25,0 \%)$ & $(100,0 \%)$ \\
\hline Total & 30 & 20 & 50 \\
& $(60,0 \%)$ & $(40,0 \%)$ & $(100,0 \%)$ \\
\hline
\end{tabular}

Pada Tabel 2 dapat diinformasikan bahwa anak autis laki-laki cenderung lebih memiliki perilaku tantrum $(44,7 \%)$ dibandingkan dengan anak autis perempuan $(25,0 \%)$. Berdasarkan uji statistik menggunakan SPSS didapatkan bahwa nilai $\mathrm{P}(0,37) \leq 0,05$ yang berarti tidak ada hubungan antara jenis kelamin dengan perilaku tantrum.

Laki- laki dan perempuan pasti tidak sama. Tidak sama dalam cara bereaksi, bertindak, dan tanggap didalam situasi yang memengaruhi setiap segi kehidupan. Perempuan biasanya sering menjadi pendengar yang baik dan dapat tanggap terhadap permasalahan. Perempuan lebih peka terhadap lingkungan, begitupun sebaliknya laki laki cenderung tidak peduli. Namun anak laki laki sebagian besar $(55,3 \%)$ tidak tantrum. Artinya anak autis laki ataupun perempuan yang terjadi tantrum biasanya terjadi pada anak autis yang hiperaktif. Tantrum juga lebih mudah terjadi pada anak-anak yang dianggap "sulit", dengan memiliki ciri ciri makan, buang air besar dan tidur tidak teratur, sulit menyesuaikan diri dengan situasi, makanan dan orang-orang baru, lambat beradaptasi terhadap perubahan, suasana hati (moodnya) lebih sering negatif, mudah terprovokasi, gampang merasa marah atau kesal dan sulit dialihkan perhatiannya. ${ }^{6}$ Hal ini terbukti bahwa dari 38 anak autis yang berjenis kelamin Laki laki sebagian besar $(55,3 \%)$ berperilaku tidak tantrum. 


\section{Pendidikan Orang Tua}

Tabel 3. Tabulasi Silang Pendidikan dengan Perilaku Tantrum

\begin{tabular}{lccc}
\hline Pendidikan & \multicolumn{3}{c}{ Perilaku Tantrum } \\
\cline { 2 - 4 } & $\begin{array}{c}\text { Tidak } \\
\text { tantrum } \\
\mathrm{n}(\%)\end{array}$ & $\begin{array}{c}\text { Tantrum } \\
\mathrm{n}(\%)\end{array}$ & $\begin{array}{c}\text { Total } \\
\mathrm{n}(\%)\end{array}$ \\
\hline Dasar & 0 & 0 & 0 \\
& $(0,0 \%)$ & $(0,0 \%)$ & $(100,0 \%)$ \\
Menengah & 4 & 6 & 10 \\
& $(40,0 \%)$ & $(60,0 \%)$ & $(100,0 \%)$ \\
Tinggi & 26 & 14 & 34 \\
& $(65,0 \%)$ & $(35,0 \%$ & $(100,0 \%)$ \\
\hline Total & 30 & 20 & 55 \\
& $(60,0 \%)$ & $(40,0 \%)$ & $(100,0 \%)$ \\
\hline
\end{tabular}

Berdasarkan hasil penelitian bahwa sebagian besar (78\%) responden (orang tua) memiliki pendidikan tinggi. Dengan uji statistik menggunakan SPSS didapatkan bahwa nilai $\mathrm{P}$ $(0,043) \leq 0,05$ yang berarti ada hubunganyang signifikan antara pendidikan orang tua dan perilaku tantrum anak. Orang tua (ibu) dengan pendidikan tinggi akan mudah menerima informasi tentang autis khusunya tentang tantrum dan mau melakukan sesuatu yang baik tentang anak autis. ${ }^{7}$

Pendidikan adalah modal ibu menerima pengetahuan tentang apa itu autis terutama anak yang mengalami tantrum. Ibu yang memiliki pendidikan tinggi dan pengetahuan yang baik, menjadikan ibu mudah menerima informasi agar anak tidak menjadi tantrum. Pendidikan yang baik maka orang tua dapat menerima segala informasi dari luar terutama tentang cara merawat anak autis, menjaga kesehatan anak autis. Sehingga orang tua terutama ibu yang ber- pendidikan dasar dan menjadi ibu rumah tangga dengan memiliki sedikit pengetahuan yang diperoleh akan kurang memahami cara bagaimana merawat anak agar tidak mudah mengalami tantrum.

\section{Pekerjaan Orang Tua}

Tabel 4. Tabulasi Silang Pekerjaan Orang Tua dengan Perilaku Tantrum

\begin{tabular}{lccc}
\hline Pekerjaan & \multicolumn{3}{c}{ Perilaku Tantrum } \\
\cline { 2 - 4 } & $\begin{array}{c}\text { Tidak } \\
\text { tantrum } \\
\mathrm{n}(\%)\end{array}$ & $\begin{array}{c}\text { Tantrum } \\
\mathrm{n}(\%)\end{array}$ & $\begin{array}{c}\text { Total } \\
\mathrm{n}(\%)\end{array}$ \\
\hline Bekerja & 20 & 14 & 34 \\
& $(58,8 \%)$ & $(41,2 \%)$ & $(100,0 \%)$ \\
Tidak & 10 & 6 & 16 \\
Bekerja & $(62,5 \%)$ & $(37,5 \%)$ & $(100,0 \%)$ \\
\hline Total & 30 & 20 & 50 \\
& $(60,0 \%)$ & $(40,0 \%)$ & $(100,0 \%)$ \\
\hline
\end{tabular}

Berdasarkan hasil penelitian hasil bahwa sebagian besar $(62,5 \%)$ orang tua yang tidak bekerja dan anaknya tidak mengalami tantrum, dan orang tua yang bekerja, sebagian besar anaknya tidak mengalami tantrum $(58,8 \%)$. Berdasarkan uji statistik didapatkan bahwa nilai $\mathrm{P}(0,000) \leq 0,01 \geq$ yang berarti ada hubungan pekerjaan dengan perilaku tantrum

Pekerjaan orang tua dapat memengaruhi pemeliharaan anak autis. Bekerja memengaruhi waktu yang dapat mereka habiskan untuk keluarga. Kebanyakan orang tua yang tidak bekerja mempunyai banyak waktu luang. Kasih sayang dan kesabaran adalah faktor utama dalam merawat anak autis khusunya anak autis yang mengalami tantrum. Terbukti Responden (ibu) yang tidak bekerja, sebagian besar $(62,5 \%)$ anaknya berperilaku tidak tantrum. 


\section{Dukungan Orang Tua}

Tabel 5. Tabulasi Silang Dukungan Orang Tua dengan Perilaku Tantrum

\begin{tabular}{lccc}
\hline Dukungan & \multicolumn{3}{c}{ Perilaku Tantrum } \\
\cline { 2 - 4 } & $\begin{array}{c}\text { Tidak } \\
\text { tantrum } \\
\mathrm{n}(\%)\end{array}$ & $\begin{array}{c}\text { Tantrum } \\
\mathrm{n}(\%)\end{array}$ & $\begin{array}{c}\text { Total } \\
\mathrm{n}(\%)\end{array}$ \\
\hline Tidak & 3 & 14 & 17 \\
Mendukung & $(17,6 \%)$ & $(82,48 \%)$ & $(100,0 \%)$ \\
Mendukung & 29 & 4 & 33 \\
& $(87,8 \%)$ & $(8,2 \%)$ & $(100,0 \%)$ \\
\hline Total & 32 & 18 & 44 \\
& $(64,0 \%)$ & $(36,0 \%)$ & $(100,0 \%)$ \\
\hline
\end{tabular}

Tabel 5 di atas menginformasikan bahwa dukungan orang tua dapat berdampak pada anak untuk tidak berperilaku tantrum $(87,8 \%)$ dibandingkan dengan orang tua yang tidak dukungan yang baik pada anak. Berdasarkan uji statistik menggunakan SPSS didapatkan bahwa nilai $\mathrm{P}(0,000) \leq 0,05$ yang berarti ada hubungan dukungan orang tua dengan perilaku tantrum anak.

Dukungan orang tua dapat diartikan orang tua sebagai komponen utama dalam kehidupan anak harus berperan penting dalam mengatasi masalah diet anak autis yaitu dengan diet free glutein dan casein. Dukungan orang tua adalah bentuk sikap, tindakan, dan penerimaan pada anak autis. Orang tua memandang bahwa orang tua yang bersifat mendukung akan selalu siap memberikan pertolongan dan bantuan jika diperlukan. ${ }^{8}$ Dukungan keluarga sangatlah penting, karena menurut peneliti, anak autis tidak bisa memakan makanan yang mengandung glutein dan casein dikarenakan anak autis alergi dengan makanan yang mengandung gluten dan kasein. Sedangkan dari 33 Responden (keluarga) yang mendukung sebagian besar $(87,8 \%)$ berperilaku tidak tantrum.

\section{SIMPULAN DAN SARAN}

\section{Simpulan}

Simpulan yang dapat ditarik dari penelitian analisis faktor-faktor yang memengaruhi perilaku tantrum pada anak autis di Yayasan Nathanisa Surabaya didapatkan bahwa faktor yang paling berpengaruh terhadap perilaku tantrum adalah dukungan dengan hasil anak dan memberikan kasih sayang itulah yang sangat dibutuhkan pada anak.

\section{Saran}

Orang tua mempunyai peranan penting dalam merawat anak autis terutama terhadap anak yang mengalami tantrum, karena orang tua yang memberikan diet free glutein dan free casein (FGFC).

\section{REFERENSI}

1. Mauren, H. Hubungan Frekuensi Konsumsi Bahan Makanan Sumber Gluten dan Kasein dengan Perilaku Autistik Anak Autis Usia 5-12 tahun. Surakarta: Universitas Muhammadiyah Surakarta, 2017.

2. Judarwanto W. Perilaku Makan Anak Sekolah. Direktorat Bina Gizi Kementerian Kesehatan Republik Indonesia. 2011.

3. Megan NS. Measuring Menu Performance by Plate Waste Analysis. I Am Diet Assoc. Hal. 112. 2014.

4. Nurdiansyah, Y. dan Hartati, S. Case-based Reasoning Untuk Pendukung Diagnosa 
Gangguan Pada Anak Autis. Universitas Jember. 2014.

5. Nugroho. Kepatuhan orang tua dalam menerapkan terapi diet gluten free casein free pada anak penyandang autisme di yayasan pelita hafizh dan SLBN Cileunyi Bandung. 2012.

6. Samsuddin. Burnout Pada Terapis Anak Berkebutuhan Khusus. E-Journal Psikologi. Vol. 1. No. 2 (187-199). 2013.

7. Notoatmodjo, S.. Metodologi Penelitian Kesehatan. Jakarta: Rineka Cipta. 2012.

8. Friedman. M. M. Buku keperawatan keluarga. Jakarta: EGC. 2010.

9. Aqila, Smart Rose. Anak Cacat Bukan Kiamat : Metode Pembelajaran dan Terapi Untuk Anak Berkebutuhan Khusus, Yogyakarta, Kata Hati, 2010.

10. Cahya, Y. Jumlah penyandang autis di Indonesia, 2016.

11. Dinantia, F. Hubungan Pola asuh orang tua dengan frekuensi dan intensitas perilaku temper tantrum pada anak toddler. 2014.

12. Nala, S.F. Hubungan Penerapan Diet Gluten Free Casein Free(GFCF) Dengan Status Gizi Anak Autisme. 2016.

13. Ghalichi, F., Ghaemmaghami, J., Malek, A., \& Ostadrahimi, A. Effect of gluten free diet on gastrointestinal and behavioral indices for children with autism spectrum disorders: a randomized clinical trial. World Journal of Pediatrics.

2016. https://doi.org/10.1007/s12519-016-0040-z

14. Ginanjar, A. S. Menjadi Orang Tua Istimewa. Jakarta : Dian Rakyat, 2008.

15. Winarno, F.G. Autisme dan Peran Pangan. Jakarta : PT. Gramedia Pustaka Utama, 2011.

16. Hayes, E. Panduan Memahami Tantrum dan Mengatasi Ledakan Emosi Anak. Jakarta. Erlangga. 2009.

17. Dwi, R.Y. Hubungan Antara Pola Asuh Orang Tua Dengan Temper Tantrum Pada
Anak Autis Di SLB AGCA Center Surak, 2016. 